\title{
Ecological and economic transformations of natural management systems of agrarian type (based on materials from the South of Russia)
}

\author{
Galina Karpova ${ }^{1}$ and Natalya Medyanik ${ }^{2, *}$ \\ ${ }^{1}$ St. Petersburg State University of Economics, St. Petersburg, Russia \\ ${ }^{2}$ North-Caucasian Federal University, branch in Pyatigorsk, Russia
}

\begin{abstract}
The necessity of ecological and economic transformations of natural management systems of the agrarian type is shown, considering dominant natural landscapes, sectoral specifics of the economy and settlement. Spatial and sectoral priorities and measures for greening of the development of natural management systems of the agrarian type, associated with climate adaptation of traditional agricultural sectors, ecosystem services, ethnically marked agricultural practices, as well as ecosystem-adaptive transformation of the agrarian economy, taking into account the specifics of steppe, mountain, rural natural management localities are substantiated.
\end{abstract}

\section{Introduction}

Due to the territorial and sectoral specifics of environmental and economic problems, their solution seems to be the most constructive within the boundaries of natural management systems localized in space and having a pronounced sectoral specialization, in our case, of the agrarian type.

In the author's interpretation, such an economic phenomenon is interpreted as a complex, polystructural and functional spatio-temporal formation constituted by the system of economic relations regarding appropriation, use, reproduction and protection of ecosystem goods (as elements of ecological systems within the framework of structural and functional integrity) in a variety of resource (productive) for agricultural production and environment-forming (life-supporting) utilities for the rural population, as well as a natural basis for ecological systems, ensuring the conflict-free co-existence of society and nature.

The ecological and economic vector of transformations of natural management systems of the agrarian type orients the economic turnover of ecosystem goods towards preservation and augmentation of productive for the agricultural economy, as well as environmentforming (life-supporting) benefits for rural areas in the framework of structural and functional integrity of ecological systems. In agar practice, such an approach involves considering the specifics of the dominant types of natural landscapes in the space of agrarian natural management systems (NMS), constituting steppe, mountainous, as well as rural types of natural management localities [1, pp. 546-563].

\footnotetext{
*Corresponding author: natalya-medyanik@yandex.ru
} 


\section{Materials and methods}

The study is based on the method of typologies, which made it possible, taking into account spatial mosaicity of landscape characteristics, sectoral specifics of the economy and settlement within the boundaries of natural management systems of the agrarian type, to identify the types of natural management localities: according to the criteria of 'dominant natural landscapes' - steppe, mountainous; 'settlement' - rural; 'economic profile' agriculture and related forestry, water industry, fisheries, waste disposal and recycling, ecosystem services, ethnically labeled agricultural practices. This approach serves as a methodological guideline in substantiating the spatial and sectoral priorities of ecological and economic transformations of natural management systems of the agrarian type [1, pp. 546-563].

The empirical base of the study was made up of information and reporting materials of state authorities, statistical spatial-dynamic series of environmental and economic data in the constituent entities of the South of the Russian Federation.

\section{Results and discussion}

Taking into account profile specialization, sectoral priorities of the ecological and economic transformation of the agrarian-type NMS within the framework of the inclusive sustainable growth concept [2] and 'greening' of the economy trends should be focused on stimulating low-carbon, resource-efficient, eco-service agrarian economy, the sectoral locomotives of which should be 'green' sectors, according to the universally recognized version of UNEP [3], as agriculture and related forestry, water industry, fisheries, waste disposal and recycling, or 'green' agro-restructuring, as well as on the maintenance of agricultural structures, traditional for the rural, private autochthonous population, completely dependent on ecosystem goods.

Structural transformations are associated with the ecosystem-adaptive orientation of the agricultural sector, focused on the production, coupled with traditional agricultural benefits of ecosystem services; moisture and water saving; forest reproduction, in particular, multifunctional field protection belts; aquaculture oriented on pharmaceuticals, feed production; alternative bioenergy; ecosystem services related to maintaining biodiversity, preserving natural ecosystems, ecological reconstruction of natural objects and restoration of natural complexes; ecological, rural, ethnic tourism; climate modernization and adaptation to climatic changes in the agricultural and related industries.

Taking into account the global and local ecosystem significance of steppe biomes [4, pp. 45102], as well as the critically important agrarian factor providing 'at least $85 \%$ of the Russian grain harvest, more than $70 \%$ of the cattle, more than $90 \%$ of sheep and goats wool' [5, p. 6], the economic turnover within the boundaries of steppe natural management localities should imply production of ecosystem services, together with traditional food benefits, otherwise the ecosystem-adaptive format of farming [6, p. 61].

Such purposes can be reached by organizing natural reserves such as 'micro-reserves' on agricultural lands withdrawn from circulation and belonging to genetically valuable steppe biomes, using fallow lands for normalized grazing, expanding the practice of natureconservation easements and encumbrances limiting the plowing of potential arable land, giving livestock access to pasture plots in order to provide them with a regime of protection or recreation of natural habitats of wild biological species, incl. due to self-renewal of natural vegetation.

Taking into account the long-term reproductive processes, according to estimates, from 10 to 60 years or more [7], such agricultural practices should be prolonged in time, provide for the 
protection status of 'reserved agricultural lands or reserved lands', as well as compensation for lost income to the owner / plotter.

There is a good chance that the status of 'Kyoto farmlands or Kyoto lands' will be given to fallow, as well as unused agricultural lands, the share of which in the area of similar lands in a number of subjects of the South amounts to 16.72-19.52 \% [8, pp. 274-275]. This will reduce the time for reproduction of natural ecosystems, prevent plowing accompanied by carbon emission, according to estimates [9, pp. 330-336] 22-26\% of the initial volume, avoid the cost of returning land to agricultural use.

In ecosystem farming, a farmland owner should be made responsible for planting and maintaining shelterbelts, preferably multipurpose, for example, using honey-producing tree and shrub species, tinning coastal strips along rivers, complying with an absolute reserve regime and, in some cases, for full-scale ecological restoration of valleys and floodplains of rivers, which have become refugia of biodiversity, as well as other biotechnical activities. A constructive example of such agricultural practices within the framework of landscape conservation initiatives is the United States [6, pp. 51, 131].

Meanwhile, $43.0 \%$ of southern agricultural lands and a number of regions, such as the Republic of Dagestan and Kalmykia, 85.0\% and 77.3\% respectively [6, C, 13], fall on pasture, the ecosystem-adaptation orientation of which should be associated with moderate grazing of mainly horses and cattle, and strictly regulated - of sheep; phytomelioration of natural pastures with grass mixtures of local species and crops and technical measures to maintain optimal composition and structure of natural pasture ecosystems; one-time haymowing within 2-3 years and regulated agricultural burnings in the early spring, etc. [1, pp. 550-551].

The use of such ecosystem adapted techniques on the steppe pastures of the South is important in the context of combating desertification. Thus, according to the recommendations of the Caspian Research Institute of Arid Agriculture, in the conditions of Astrakhan steppes, without prejudice to natural regeneration, the removal of pasture plants should not exceed 50$60 \%$ of the annual growth [10, p. 25].

Equally, the ecosystem adaptation approach is relevant in mountain pastures, where unregulated grazing and haymaking in the conditions of 'vulnerable' alpine and subalpine ecosystems is accompanied by sustained degradation of soil and vegetation cover, a decrease in bioproductivity and fodder value of natural lands. For example, about $80 \%$ of the largest pasture tracts of Kabardino-Balkaria belong to the erosion-hazardous area, and 1/3 of them are covered by poisonous and weedy plants [11, p. 60]. This is not surprising, since the last cultural and technical activities in mountain pastures were carried out by Kabbalkselkhozkhimiya in 1983 [11, p. 61]

Obviously, in the practice of managing both in the conditions of mountainous and steppe landscapes, mandatory rehabilitation of pasture lands should be imputed, serving as a criterion for agricultural supervision and land control.

In general, the ecosystem adaptation determinants of agricultural management in the conditions of mountain natural management localities, which in a number of constituent entities of the South of the Russian Federation account for from 26.8 (Krasnodar Krai) to 98\% (Karachay-Cherkessia), should take into account the unique ecosystem functionality of mountain biomes and consider them as a place of application of ethnic environmental agricultural practices [12].

In this regard, the emphasis should be placed on mobilizing the productive potential of agrarian ethnoeconomics, or capitalizing the creative natural management competencies of mountain communities, for example, in such traditional agricultural practices as collection and processing of wild berries, nuts, mushrooms, medicinal raw materials, madder breeding, beekeeping, horse and sheep breeding, as well as relatively new ones, such as ethnic and rural tourism, plantation cultivation of wild plants, medicinal plants and forestry [6, pp. 115 - 123]. 
In the absence of agrochemical pressure, mountainous localities can serve the development of organic farming, forming competitive advantages for mountain households on the market of ecologically clean agricultural products [13, pp. 105-116].

Equally low- and medium-altitude zones (altitudes above sea level from 400 to $2000 \mathrm{~m}$ ) are suitable for cultivation of fruits based on intensive technologies that provide, as the experience of Kabardino-Balkaria shows, more than three times the yield and profitability of $180 \%$ compared to traditional gardening, and also in the belt of low mountains, in particular the Western Caucasus - citrus and subtropical crops, tea [14, pp. 140-143].

Given the agrarian orientation of the economy and rural lifestyle for 6,137,820 people, or $37.3 \%$ of the population, as well as taking into account that $86.5 \%$ of settlements in the South of the Russian Federation are non-urbanized [15, p. 40], it is legitimate to distinguish rural natural management localities.

This approach corresponds to the integrated model widespread in the EU countries, where sustainable development of rural areas and the agricultural sector is interdependent (Sustainable Agriculture and Rural Development, CAP) [16], and also resembles rural policy in OECD countries based on multisectoral, service approach, which involves all the advantages of rural areas, including ecosystems, into the circulation of local ecosystem assets [17].

In this regard, considering the dominance in the rural economy of the South of the Russian Federation of small commodity structures in the form of farms and personal subsidiary plots, the above-mentioned model of capitalization of the creative competencies of rural households may be in demand [6, pp. 116, 121].

The sectoral platform for capitalization can include not only agricultural and food production, biological fishing, artistic crafts, but also organic farming and animal husbandry, agro- and ecotourism, forestry, alternative energy, bioeconomics, ecosystem services, which are in demand in the context of greening.

As such industries develop, an ecosystem adapted transformation of rural space into ecovillages is likely, and their functioning is carried out on the principles of ecopolis based on self-organization of citizens and joint responsibility for the improvement of rural residential environment, as well as natural complexes [18].

In this sense, rural areas can play a key role in the production of ecosystem services, or the development of 'green infrastructure' [19, pp. 474 - 482].

Ecosystem services are especially in demand in old-developed agricultural areas, where long-term large-scale agricultural transformation is aggravated by the scarcity and low zonal representativeness of protected areas, smoothing of landscape differences, a decrease in the productivity and sustainability of agricultural landscapes, which are a refuge for numerous biological species. It is possible to resist destructive processes by preservation or full-scale restoration of natural areas, as well as ensuring the optimal spatial and sectoral structure of land use, according to estimates [20, p. 28] up to $30 \%$ of which should be allocated to zones of natural rest, and in the rest of the territory to ensure the optimal ratio of arable land, forests, fodder and other lands.

Production of ecosystem services with a high return on investment from 3 to 75 times [21], can be implemented in such areas as carbon market, specially protected natural areas, biodiversity, comfortable residential areas, etc.

Thus, the offer of carbon-depositing services can be organized within the framework of implementation of business projects in the field of afforestation and orientation of agricultural producers, for example, to no-till technology. In addition, for the South of the country, taking into account low forest cover and the need for anti-erosion protection, such measures would allow for the reproduction of forest resources and soil fertility, as well as in the channel of the low-carbon economy for reducing carbon emissions, since, according to estimates [22, P. 88] 
$20-30 \%$ of the increase in carbon emissions is due to deforestation and land use change, most notably plowing farmland.

\section{Conclusions}

Based on the research results, the following conclusions and recommendations were obtained:

1. Structural ecological and economic transformations of the natural management system of the agrarian type are associated with ecosystem-adaptive orientation of the agrarian sector, focused on production, coupled with traditional agricultural benefits of ecosystem services; moisture and water saving; forest reproduction, in particular, multifunctional field protection belts; aquaculture oriented, including pharmaceuticals, feed production; alternative bioenergy; ecosystem services related to maintaining biodiversity, preserving natural ecosystems, ecological reconstruction of natural objects and restoration of natural complexes; ecological, rural, ethnic tourism; climate modernization and adaptation to climatic changes in the agricultural and related industries.

2. Spatial ecological and economic transformations in the natural management system of the agrarian type include taking into account specifics of the dominant types of landscapes and the nature of settlement, assuming an ecosystem adaptive format of farming and pasture management within the boundaries of steppe localities; mountain localities - capitalization of the creative natural-economic competencies of ethnic communities, or ethnically marked agrarian practices; rural areas - property and economic specification, long-term productivity of land benefits as a key factor of production and a source of well-being for rural and ethnic communities, 'green', climate-adapted transformations of traditional agricultural sectors, stimulation of ecosystem services.

\section{References}

1. N.V. Medyanik, In the world of scientific discoveries, 49, 546-563 (2014)

2. G20, Incorporating Green Growth and Sustainable Development Policies into Structural Report Agendas: A Report for the G20 Summit, Los Cabos (2012)

3. UNEP, Towards Green Economy: Pathways to Sustainable Development and Poverty Eradication: Synthesis Report for Policy Makers (2011)

4. I.E. Smelansky, A.A. Tishkov, Eurasian Steppes. Ecological Problems and Livelihoods in a Changing World: textbook (2012)

5. N.A. Sobolev, Development of Legal Measures for the Protection of Steppe Ecosystems Outside Protected Areas (2010)

6. N.V. Medyanik, Priorities for Greening Socio-Economic Development of the Southern Metaregion of Russia (2020)

7. N. Vuichard, P. Ciais, L. Belelli, P. Smith, R. Valentini, Global Biogeochem. Cycles, 22 (2008)

8. Report on the state and use of agricultural land in the Russian Federation in 2017 (2018)

9. E.A. Mikhailova, C.J. Post, European Journal of Soil Science, 57, 330-336 (2006)

10. V.P. Zvolinsky, M.M. Shagaipov, G.K. Bulakhtina, Bulletin of Russian Agricultural Science, 2, 23-25 (2011)

11. On the state and protection of natural environment in the Kabardino-Balkarian Republic in 2018: Report (2019)

12. UN, Agenda for $21^{\text {st }}$ century. Adopted by the United Nations Conference on Environment and Development (1992) 
13. R.D. Albegonova, V.I. Ugorets, Mining Agriculture, 1, 105-116 (2018)

14. FGBNU VNIIZiZPE, Collection of reports of the All-Russian scientific and practical conference with international participation, Kursk, September 14-16 (2016)

15. Rosstat, Regions of Russia. Socio-economic indicators. 2019: Stat. Coll. (2019)

16. European Commission, Common agricultural policy. The common agricultural policy supports farmers and ensures Europe's food security (2021)

17. OECD Regional Development Ministeria, Principles on Urban Policy and on Rural Policy (2019)

18. P. F. Downton, Ecopolis - Architecture and Cities for a Changing Climate. Future City: textbook (2009)

19. H.A. Hovhannisyan, G.S. Nersisyan, Procedia Environmental Sciences, 37, 474—482 (2017)

20. Center for Biodiversity Conservation, Strategy for Management of National Parks in Russia (2002)

21. UNEP, Dead Planet, Living Planet - Biodiversity and ecosystem restoration for sustainable development. A rapid response Assessment (2010)

22. World Bank, The Growth Report. Strategies for Sustained Growth and Inclusive Development (2009) 